\title{
Study of Vitamin D, hs-CRP and Lipid Profile Status in Newly Diagnosed Hypothyroid Patients in the Local Population of Kanchipuram District
}

\author{
Sumanth Kumar B ${ }^{1 *}$, Ursula Sampson ${ }^{1}$, J.Pratheeba ${ }^{2}$, K.Ponnazhagan ${ }^{3}$ \\ ${ }^{1,2}$ Assistant Professor, ${ }^{1}$ Professor and HOD, ${ }^{3}$ Research scholar, Department of Biochemistry, Meenakshi Medical College Hospital and Research \\ Institute, Enathur, Kanchipuram, Tamilnadu-631552, India
}

DOI: $\underline{10.36348 / \mathrm{sijb} .2020 . \mathrm{v} 03 \mathrm{i} 09.003}$

| Received: 10.09.2020 | Accepted: 23.09.2020 | Published: 26.09 .2020

*Corresponding author: Sumanth Kumar B

\section{Abstract}

Background: Thyroid dysfunction is relatively a common disease which affects people, irrespective of their age and gender. Hypothyroidism is a clinical syndrome resulting from deficiency of thyroid hormones, which in turn results in a generalized slowing down of the metabolic processes. Newly diagnosed hypothyroidism has been reported to be associated with inflammation, dyslipidemia which leads to CV risk. hs-CRP is a marker of subclinical inflammation and a predictor of CVD. Vitamin D deficiency is involved in autoimmune diseases, metabolic syndromes, cardiovascular disease, and cancers. Recent evidence has demonstrated an association between low vitamin D status and autoimmune thyroid diseases. Objectives: The aim of the present study was to compare vitamin D, hs CRP levels and lipid profile with that of thyroid profile among newly diagnosed hypothyroid subjects. Materials and methods: A total of 70 subjects with the clinical features and investigative reports suggestive of hypothyroidism and newly diagnosed as hypothyroid patients in General Medicine department, Meenakshi medical college, kanchipuram, were compared with 70 healthy controls. Results: The levels of vitamin D were significantly reduced compared to controls and negatively correlate with TSH in hypothyroid cases. hs-CRP levels were significantly increased and positively correlate with TSH in hypothyroid patients. Total cholesterol and TGL levels were significantly higher compared to control group and positively correlate with TSH in hypothyroid cases but the level of HDL was significantly reduced compared to controls and negatively correlate with TSH in hypothyroid patients. Conclusion: Our results indicated that newly diagnosed hypothyroid patients become an important entity due to possible link between diagnosed hypothyroid patients and cardiovascular risk factors, especially lipid abnormalities and alteration of BMI levels. Patients with hypothyroidism suffered from hypovitaminosis $\mathrm{D}$ and also significant association between TSH and hs-CRP is an important finding in this study.

Keywords: Hypothyroid, vitamin D, hs-CRP and dyslipidemia.

Copyright @ 2020: This is an open-access article distributed under the terms of the Creative Commons Attribution license which permits unrestricted use, distribution, and reproduction in any medium for non-commercial use (NonCommercial, or CC-BY-NC) provided the original author and source are credited.

\section{INTRODUCTION}

Thyroid disorders are the most common endocrinopathies throughout the world [1]. Among all the thyroid disorders in the world, frequency of hypothyroidism is around 2\% [2]. In the world, India is in the second position where thyroid disorders are the most common glandular disorders of the endocrine system [3].

Hypothyroidism is a clinical syndrome resulting from deficiency of thyroid hormones, which in turn results in a generalized slowing down of the metabolic processes [4]. Thyroid dysfunction is relatively a common disease which affects people, irrespective of their age and gender. Incidence of hypothyroidism will vary depending on the geographical and the environmental factors such as dietary iodine, the genetic characteristics of the population and the age distribution of the population. Hypothyroidism affects the cardiovascular, pulmonary, renal, nervous and the reproductive systems. Most of the cardiovascular disorders are associated with derangement in the lipid metabolism [5].

Serum thyroid hormones will have a serious impact on lipid profile. Thyroid hormones will have effect not only on the synthesis of the lipids but also on their degradation [6]. These thyroid hormones will affect the lipid levels in the serum mainly by regulating the gene expression which is involved in the metabolism of lipids [7]. HMG- Co a reductase enzyme is the key enzyme in the synthesis of cholesterol. Thyroid hormones will play a major role in upregulating the expression of the gene for HMG- Co enzyme a reductase, through its nuclear receptors. At 
the same time, thyroid hormones will also upregulate low density lipoprotein (LDLc) receptors through gene activation. Thyroid hormones stimulate tissue lipoproteinlipase enzyme and influence the serum triglyceride levels. These hormones will activate cholesteryl-ester transfer protein (CETP) and thereby reduce the serum HDL levels. They also increase the expression of HDL receptors in the liver and help in reverse cholesterol transport [8].

Vitamin D is structurally similar to the steroids and it is mainly synthesized in the skin, which regulates the expression of a large number of genes [9]. Regulating the bone metabolism and also maintaining the homeostasis of calcium and phosphorus is the major function of vitamin D. Recent evidence shows that the deficiency of vitamin D can cause not only the skeletal problems but also non-skeletal problems like autoimmune diseases, certain cancers, metabolic syndromes, diseases related to cardiovascular system, infections etc [9-11]. Certain autoimmune thyroid diseases like Hashimoto's thyroiditis (HT) and Graves' disease (GD) have been found to be associated with the vitamin $\mathrm{D}$ deficiency. It has been reported that impaired function of vitamin D can increase formation of thyroid tumors [12-14].

It was found that similar receptors are involved in the binding of Vitamin D and thyroid hormones. Those receptors are called steroid hormone receptors. At the same time, a different gene in the Vitamin D receptor was found to be involved in causing autoimmune thyroid diseases like Graves' disease and Hashimoto's thyroiditis. Because of these particular reasons, it is very much needed to know about the functioning of vitamin $\mathrm{D}$ in thyroid patients[15] Vitamin D will show its actions by binding to vitamin D receptor (VDR) and activates VDR-responsive genes. VDR gene polymorphism was found to be associated with autoimmune thyroid diseases (AITDs) [16].

Immune system will also be greatly influenced by Vitamin $D$, where vitamin $\mathrm{D}$ enhances the innate immune response and at the same time it will inhibit the adaptive immune system [17]. Most of the immune cells like $\mathrm{T}$ cells, $\mathrm{B}$ cells and antigen-presenting cells (APCs) such as dendritic cells (DCs) and macrophages, express VDR and 1-hydroxylase [18].

High sensitive C-reactive protein (hs-CRP) is an important and sensitive marker of subclinical inflammation. Hs-CRP might be a key molecule linking the inflammation to oxidative stress in atherosclerosis leading to $\mathrm{CV}$ risk $[19,20]$. In the patients with hypothyroidism, the main reason for the inflammatory process could be because of TSH induced synthesis of TNF. Another important reason for this inflammatory process could be because of Cyclooxygenase- 2 (COX 2) which increases the production of autocoids that will cause the inflammation [21].

\section{AIMS AND OBJECTIVES}

The aim of the present study was to compare vitamin D, hs CRP levels and lipid profile with that of thyroid profile among newly diagnosed hypothyroid subjects.

\section{MATERIALS AND METHODS}

A cross-sectional study was carried out in Meenakshi Medical College Hospital and Research Institute, Kanchipuram, the study includes 70 subjects with the clinical features and investigative reports suggestive of hypothyroidism and newly diagnosed as hypothyroid patients in General Medicine department, Meenakshi medical college, kanchipuram, which were compared with 70 healthy controls. Hypothyroid patients who are in the age group of 20-45 years of age, as well as euthyroid groups were enrolled for the study. This study was ethically approved by the institutional ethical committee. Age and Body mass index was quantified by bioelectrical impedance analysis. TSH, fT4, fT3, total cholesterol (TC), triglycerides (TGL), HDL-C levels along with Vitamin D and hs-CRP were estimated in all the participants.

Every participant voluntarily participated in the research work. $5 \mathrm{ml}$ of fasting venous blood will be taken from the subject after taking informed consent from the subjects who are included in our study. Thyroid function tests were measured by (AccuBind Performance Materials, Tosho PVT.LID, India) kit using Chemiluminescence Immunoassay (CLIA). Vitamin D and hs-CRP were estimated by CLIA (Biotech PVT.LID) kits. These Kits were used for investigation in aforesaid population. Total cholesterol, triglycerides, HDL-cholesterol was investigated by CHOD/POD method, GPO-PAP method and CHODPOD/ Phosphotungstate method respectively. (Diasys) kits were used for the investigation.

\section{STATISTICS}

Analysis was done by using SPSS version-21.0 version. All the baseline characteristics (age, body mass index, TSH, fT4, fT3, total cholesterol, triglycerides, HDL-C, vitamin D and hs-CRP) were expressed in Mean \pm SD. To analyse the difference among different parameters of newly diagnosed subclinical hypothyroid patients group and control group, Independent t-test was used. An association between TSH and lipid profile, Vitamin D and Hs-CRP in the newly diagnosed subclinical hypothyroidism group was analysed using pearson correlation coefficient test. A p-value $<0.05$ was considered statistically significant.

\section{The inclusion criteria}

- Patients with weight gain, muscle cramps, thyroid swelling, generalized weakness and easy fatigability, primary infertility and menorrhagia.

- Patients in the age group of 20-45 years. 


\section{The exclusion criteria}

- Patients with coronary heart disease or any acute illness.

- Patients who are on drugs which affect the thyroid function like anti thyroid drugs, OC pills, steroids etc.

- Pregnant women

- Disorders which affect the lipid metabolism like diabetes mellitus or renal failure and those people who are on lipid lowering drugs.

\section{RESULT}

Data depicted in Table-1 represent the comparison of controls and cases according to age and BMI. The mean age of controls and cases in our study was found to be $33.43 \pm 11.57$ years and $32.83 \pm 10.32$ years respectively. BMI values in the study were significantly increased $(\mathrm{P}<0.001)$ in the hypothyroid patients, when compared with the control group.

Table-1: Comparison of controls and cases according to age and BMI

\begin{tabular}{|l|l|l|l|}
\hline Parameters : Mean \pm SD & Control $\mathbf{n}=\mathbf{7 0}$ & Hypothyroid $\mathbf{n}=70$ & $\mathbf{t}$ - value, $\mathbf{p}$ - value \\
\hline Age & $33.43 \pm 11.57$ & $32.83 \pm 10.32$ & $\mathrm{NS}$ \\
\hline $\mathrm{BMI}(\mathrm{Kg} / \mathrm{m} 2)$ & $21.4 \pm 1.51$ & $31.2 \pm 2.33$ & $\mathrm{t}=-29.56, \mathrm{P}<0.001^{* *}$ \\
\hline
\end{tabular}

Table 2 shows, comparison of biochemical parameters between controls and cases. In the study, the mean TSH levels were increased significantly in cases $(\mathrm{P}<0.001)$, compared to control group. However, fT3 and fT4 were reduced significantly $(\mathrm{P}<0.001)$, when compared to controls. The levels of vitamin D were significantly decreased in cases $(\mathrm{P}<0.001)$, compared to control group. The mean hs-CRP levels in control groups was within the reference range, but it was significantly increased $(\mathrm{P}<0.001)$ in hypothyroid patients. When compared with the control group, the total cholesterol levels were significantly higher $(\mathrm{P}<0.001)$ in hypothyroid patients.

The level of TGL were significantly $(\mathrm{P}<0.001)$ increased compared to controls and the mean HDL levels of hypothyroid patients were significantly lower $(\mathrm{P}<0.001)$, than control groups.

Table-2: Comparison of controls and cases with biochemical parameter

\begin{tabular}{|l|l|l|l|}
\hline Parameters : Mean \pm SD & Control & Hypothyroid & t- value, $\mathbf{p}-$ value \\
\hline TSH $(\mu \mathrm{IU} / \mathrm{ml})$ & $2.63 \pm 1.72$ & $37.89 \pm 27.69$ & $\mathrm{t}=-10.63, \mathrm{P}<0.001^{* * *}$ \\
\hline fT3 $(\mathrm{pg} / \mathrm{ml})$ & $1.94 \pm 0.77$ & $1.26 \pm 0.43$ & $\mathrm{t}=15.47, \mathrm{P}<0.001^{* *}$ \\
\hline fT4 $(\mathrm{ng} / \mathrm{dl})$ & $1.22 \pm 0.33$ & $0.62 \pm 0.22$ & $\mathrm{t}=12.3, \mathrm{P}<0.001^{* *}$ \\
\hline Vitamin D $(\mathrm{ng} / \mathrm{ml})$ & $40.0 \pm 9.96$ & $18.84 \pm 7.3$ & $\mathrm{t}=11.18, \mathrm{P}<0.001^{* * *}$ \\
\hline hs-CRP $(\mu \mathrm{g} / \mathrm{ml})$ & $2.22 \pm 0.93$ & $10.18 \pm 3.3$ & $\mathrm{t}=-18.84, \mathrm{P}<0.001^{* *}$ \\
\hline Total $\mathrm{Cholesterol}(\mathrm{mg} / \mathrm{dl})$ & $168.5 \pm 7.27$ & $271.2 \pm 25.6$ & $\mathrm{t}=-32.25, \mathrm{P}<0.001^{* *}$ \\
\hline TGL $(\mathrm{mg} / \mathrm{dl})$ & $136.8 \pm 5.57$ & $281.0 \pm 28.6$ & $\mathrm{t}=-41.5, \mathrm{P}<0.001^{* *}$ \\
\hline HDL $(\mathrm{mg} / \mathrm{dl})$ & $47.34 \pm 7.0$ & $34.5 \pm 2.91$ & $\mathrm{t}=14.0, \mathrm{P}<0.001^{* *}$ \\
\hline
\end{tabular}

Table 3 shows, vitamin D levels were within reference range for $7.1 \%$ of cases and $80 \%$ of controls.
Vitamin D levels are below the reference range in $92.9 \%$ of cases and in only $20 \%$ of controls

Table-3: Distribution of control and cases according to their Vitamin D

\begin{tabular}{|l|l|l|l|}
\hline & Values & Control & Hypothyroid \\
\hline \multirow{2}{*}{ Vitamin D } & $<30$ & $14(20 \%)$ & $65(92.9 \%)$ \\
\cline { 2 - 4 } & $>30$ & $56(80 \%)$ & $5(7.1 \%)$ \\
\hline \multicolumn{2}{|c|}{ Total } & $\mathbf{7 0}(\mathbf{1 0 0 \%})$ & $\mathbf{7 0}(\mathbf{1 0 0 \% )}$ \\
\hline
\end{tabular}

Table 4 shows, hs- CRP levels were within reference range for $12.9 \%$ of cases and $90 \%$ of controls.
hs-CRP levels were above the reference range in $87.1 \%$ of cases and in only $10 \%$ of controls.

Table-4: Distribution of control and cases according to their hs-CRP

\begin{tabular}{|c|l|l|l|}
\hline & Values & Control & Hypothyroid \\
\hline \multirow{2}{*}{ Hs-CRP } & $<3$ & $63(90 \%)$ & $09(12.9 \%)$ \\
\cline { 2 - 4 } & $>3$ & $7(10 \%)$ & $61(87.1 \%)$ \\
\hline \multicolumn{2}{|c|}{ Total } & $\mathbf{7 0}(\mathbf{1 0 0 \% )})$ & $\mathbf{7 0}(\mathbf{1 0 0 \%})$ \\
\hline
\end{tabular}

(Table 5) As per Pearson's correlation, there was a significant positive correlation between TSH and total cholesterol, TGL levels [ $(\mathrm{r}=0.66, \mathrm{p}<0.01),(\mathrm{r}=0.58$, $\mathrm{p}<0.01)]$, respectively, but there was negative correlation between TSH and HDL level in hypothyroid cases $(\mathrm{r}=0.19, \mathrm{p}<0.01)$, and there were significant negative correlation between TSH and vitamin $\mathrm{D}(\mathrm{r}=-$ $0.22, \mathrm{p}<0.05)$. The level of BMI and hs-CRP positively correlate with TSH $[r=0.16, p<0.04 \& r=0.57, p<0.01)]$, respectively. 
Table-5: Pearson's correlation coefficient between TSH and other biochemical parameters in hypothyroid patients

\begin{tabular}{|l|l|l|}
\hline Parameters : Mean \pm SD & r- value & p- value \\
\hline TSH VS Total Cholesterol & 0.66 & $\mathrm{P}<0.01^{* *}$ \\
\hline TSH VS TGL & 0.58 & $\mathrm{P}<0.01^{* *}$ \\
\hline TSH VS HDL & -0.08 & $\mathrm{P}<0.03^{* *}$ \\
\hline TSH VS BMI & 0.16 & $\mathrm{P}<0.04^{* *}$ \\
\hline TSH VS Vitamin D & -0.22 & $\mathrm{P}<0.05^{* *}$ \\
\hline TSH VS Hs-CRP & 0.57 & $\mathrm{P}<0.01^{* *}$ \\
\hline
\end{tabular}

\section{DISCUSSION}

The aim of the present study was to analyse the relationship between vitamin D, hs-CRP levels and lipid profile with that of thyroid profile among newly diagnosed hypothyroid patients.

A total of 140 subjects participated in this study. Out of the total 140 subjects, 70 subjects were newly detected hypothyroid subjects (cases) and 70 were healthy controls. Both the cases and controls were age matched. The mean age of controls and cases was $33.43 \pm 11.57$ years and $32.83 \pm 10.32$ years respectively. Thyroid dysfunction is a common endocrine disorder with its prevalence increasing with age. In the present study, BMI was higher in hypothyroid cases compared to normal control group. BMI levels had significant positive correlation ( $\mathrm{r}=0.16$, $\mathrm{p}<0.04)$ when compared with TSH in hypothyroid patients. Study conducted by Nivedita Nanda et al. [22], reported similar observation with BMI in hypothyroidism. Thyroid hormones mediate their effects mainly through mechanism that stimulate basal metabolic rate, increase ATP expenditure, and modulate adrenergic receptor number and responsiveness to catecholamines. Hypothyroid state characterized by slowing down of basal metabolic rate may be an important factor contributing to increase BMI in these cases.

The mean level of serum TSH was significantly increased in hypothyroid subjects compared to control group $(37.89 \pm 27.69 \& 2.63 \pm$ $1.72)$ respectively and was statistically significant ( $\mathrm{p}<0.001)$. The mean serum fT3 levels $(1.26 \pm 0.43 \&$ $1.94 \pm 0.77)$ and serum fT4 levels $(0.62 \pm 0.22 \& 1.22 \pm$ $0.33)$ were significantly reduced $(\mathrm{p}<0.001)$, when compared to control group. Study done by Mohsin Shafi et al. on newly detected hypothyroid patients found that mean TSH levels higher in cases as compared to controls $(14.3 \pm 10.1 \mathrm{mIU} / \mathrm{L}$ vs $1.8 \pm 0.7)$ and was statistically significant $(\mathrm{p}<0.01)$ [23].

Vitamin D is known for its primary role in bone and mineral homeostasis, and it has been shown recently that its deficiency is associated with various diseases such as cardiovascular diseases, cancer, infection, and adiposity as well as osteoporosis [24]. Interestingly, it has been shown recently that vitamin D has potent immunomodulatory effects and plays an important role in the pathogenesis of autoimmune diseases. In our study the levels of vitamin D were significantly decreased in hypothyroid patients, compared to control group $(18.84 \pm 7.3 \& 40.0 \pm 9.96)$ respectively and was statistically significant $(\mathrm{p}<0.001)$. Serum vitamin $D$ levels had significant negative correlation $(r=-0.22, p<0.05)$ when compared with TSH in hypothyroid patients. Byron Richards et al. [25] suggested that, lack of vitamin D will contribute to the possibility of low thyroid hormones.

Thyroid hormones play a crucial role in regulation of immune system and high sensitive creactive protein (hs -CRP) is a marker of subclinical inflammation. In the present study the mean level of serum hs-CRP levels in control groups was within the reference range, but it was significantly increased $(\mathrm{P}<0.001)$ in hypothyroid patients. Serum hs-CRP levels had significant positive correlation $(r=0.57$, $\mathrm{p}<0.01$ ) when compared with TSH in hypothyroid patients. Duntas et al., suggested that subclinical hypothyroidism has been strongly associated with dyslipidemia and cardiovascular risk along with abnormal C- reactive protein level [26]. Xiang et al. concluded that subclinical hypothyroid patients have presented with increased symptoms of cardiovascular diseases because of altered lipid profile and hs-CRP [27].

Thyroid autoimmunity plays an important role in the elevation lipid profile. According to the Victoria Kshetrimayum study, dyslipidemia is a common finding in patients with clinical hypothyroidism, consisting of high levels of total cholesterol, TGL but HDL-c levels were low. The detected abnormalities in the lipid components are significantly improved after thyroxine replacement treatment. Present study suggested that the levels of total cholesterol and TGL were significantly higher $(\mathrm{P}<0.001)$ in hypothyroid patients compared to controls and the mean level of serum HDL of hypothyroid patients were significantly lower $(\mathrm{P}<0.001)$, than control groups. As per Pearson's correlation, there was a significant positive correlation between TSH and total cholesterol, TGL levels [( $\mathrm{r}=$ $0.66, p<0.01),(r=0.58, p<0.01)]$, respectively, but there was negative correlation between TSH and HDL level in hypothyroid cases $(\mathrm{r}=-0.08, \mathrm{p}<0.03)$.

\section{CONCLUSION}

Our results indicated that newly diagnosed hypothyroid patients become an important entity due to 
possible link between diagnosed hypothyroid patients and cardiovascular risk factors, especially lipid abnormalities and alteration of BMI levels. Patients with hypothyroidism suffered from hypovitaminosis D and also significant association between TSH and hsCRP is an important finding in this study. In view of the findings of this study, newly diagnosed hypothyroid patients become an important entity to be screened for cardiovascular risk factors, and hypovitaminosis D.

\section{REFERENCE}

1. Jha, S., Ahmad, N. (2013). Prevelance of Thyroid Dysfunction in the patients visiting Tertiary Health care hospital, Faridabad; Haryana. Int J Sci Res, 2(10).

2. Vanderpump, M.P.J. (2011). The Epidemiology of thyroid disease. Br Med Bull, 99:39-51.

3. Kochupillai, N. (2000). Clinical endocrinology in India. Curr Sci, 79:1061-1067.

4. Greenspan, F.S. (2004). The thyroid gland. In: Greenspan FS \& Gardner DG (eds). Basic \& Clinical Endocrinology. $7^{\text {th }}$ edn. New York: The McGraw-Hill Companies, 215-294.

5. De Castro, A.V., Bononi, A.P., Aragon, F., Padovani, C.R., Nogueira, C.R., Mazeto, G.M., Pimenta. (2001). Clinical and laboratory evaluation of hyperlipemic and hypothyroid patients. Arq Bras Cardiol, 76: 119-26.

6. Hariharan, S., Padhi, S., Jayaprakash, S. (2015). Dyslipidemia in hypothyroid subjects with Hashimotos thyroiditis. Int J Med Sci Public Health, 4(9):1172-1175.

7. Yun, Y.L., Gregory, B. (2009). Thyroid Hormone Crosstalk with Nuclear Receptor Signaling in Metabolic Regulation. Trends Endocrinol Metab, 21(3):166-173.

8. Rizos, C.V., Elisaf, M.S., Liberopoulos, E.N. (2011). Effects of Thyroid Dysfunction on Lipid Profile. Cardiovasc Med J, 5:76-84.

9. Makariou, S., Liberopoulos, E.N., Elisaf, M., Challa, A. (2011). Novel roles of vitamin D in disease: What is new in 2011? Eur. J. Intern. Med, 22, 355-362.

10. Holick, M.F. (2007). Vitamin D deficiency. N. Engl. J. Med, 357, 266-281.

11. Plum, L.A., DeLuca, H.F. Vitamin, D. (2010). Disease and therapeutic opportunities. Nat. Rev. Drug Discov, 9, 941-955.

12. Muscogiuri, G., Tirabassi, G., Bizzaro, G., Orio, F., Paschou, S.A., Vryonidou, A., Balercia, G., Shoenfeld, Y., Colao, A. (2015). Vitamin D and thyroid disease: To D or not to D? Eur. J. Clin. Nutr. 2015, 69, 291-296.

13. Kmie'c, P., Sworczak, K. (2015). Vitamin D in thyroid disorders. Exp. Clin. Endocrinol. Diabetes, 2015, 123, 386-393.
14. Vondra, K., Stárka, L., Hampl, R. (2015). Vitamin $\mathrm{D}$ and thyroid diseases. Physiol. Res, 64, S95S100.

15. Theodore, C. Friedman. Vitamin D Deficiency and Thyroid Disease.

www.goodhormonehealth.com/VitaminD.

16. Hollick, M.F., Chen, T.C. (2008). Vitamin D deficiency a worldwide problem with health consequences. Am J Clin Nutr, 87:10805-68.

17. Yun, Y.L., Gregory, B. (2009). Thyroid Hormone Crosstalk with Nuclear Receptor Signaling in Metabolic Regulation. Trends Endocrinol Metab, 21(3):166-173.

18. Melpomeni, P., Grigoria, B., George, D. (2011). Lipid Abnormalities and Cardiometabolic Risk In Patients With Overt And Subclinical Thyroid Disease. J Lipids.

19. Singh, S., Dey, P.S. (2014). Serum lipids, tHcy, hsCRP, MDA and PON-1 levels in SCH and overt hypothyroidism: effect of treatment. Acta Bomed, 85(2):127-134.

20. Kushner, I., Sehgal, A.R. (2002). Is high-sensitivity C-reactive protein an effective screening test for cardiovascular risk? Arch Intern Med, 162:867869.

21. Taddei, S., Ceraccio, N. (2006). Low grade systemic inflammation causes endothelial dysfunction in patients with Hashimotos Thyroiditis. J Clin Endocrinol Metab, 91:50765082.

22. Nivedita, N., Zachariah, B., Hamide, A. (2012). Insulin Resistance among Hypothyroid Patients in India. Asian J Biochem, 7(3):151-157.

23. Mohsin, S., Azim, W., Nawaz, M.A. (2013). Effect of Hypothyroidism on Lipid Profile in Asymptomatic Newly Diagnosed Patients. Biomedica, 29:12-15.

24. Vilarrasa, N., Vendrell, J., Maravall, J., El10o, I., Solano, E., \& San, Jose, E. (2010). Is plasma $25(\mathrm{OH}) \mathrm{D}$ related to adipokines, inflammatory cytokines and insulin resistance in both a healthy and morbidly obese population? Endocrine, $38(2): 235-42$.

25. Byron, R. (2008). Low Vitamin D Contributes to Thyroid Problems. Health news.

26. Duntas, L.H., Wartofsky, L. (2007). Cardiovascular risk and subclinical hypothyroidism: focus on lipids and new emerging risk factors. What is the evidence? Thyroid, 17(11):1075-84.

27. Xiang, G.D., Pu, J., Sun, H., Zhao, L., Yue, L., Hou, J. (2009). Regular aerobic exercise training improves endothelium-dependent arterial dilation in patients with subclinical hypothyroidism. Eur $J$ Endocrinol, 161(5):755-61. 